\title{
Population control of an overabundant species achieved through consecutive anthropogenic perturbations
}

\author{
Ana Payo-Payo, ${ }^{1,4}$ Daniel Oro, ${ }^{1}$ José Manuel Igual, ${ }^{1}$ Lluís Jover,,${ }^{2}$ Carolina Sanpera, ${ }^{3}$ \\ and Giacomo Tavecchia ${ }^{1}$ \\ ${ }^{1}$ Population Ecology Group, IMEDEA (CSIC-UIB), Miguel Marqués 21, Esporles 07190 Spain \\ ${ }^{2}$ Departament de Salut Pública, Facultat de Medicina, Universitat de Barcelona, Casanova 143, Barcelona 08036 Spain \\ ${ }^{3}$ Departament de Biologia Animal (Vertebrats), Facultat de Biologia, Universitat de Barcelona, Diagonal 643, Barcelona 08028 Spain
}

\begin{abstract}
The control of overabundant vertebrates is often problematic. Much work has focused on population-level responses and overabundance due to anthropogenic subsidies. However, far less work has been directed at investigating responses following the removal of subsidies. We investigate the consequences of two consecutive perturbations, the closure of a landfill and an inadvertent poisoning event, on the trophic ecology $\left(\delta^{13} \mathrm{C}, \delta^{15} \mathrm{~N}\right.$, and $\left.\delta^{34} \mathrm{~S}\right)$, survival, and population size of an overabundant generalist seabird species, the Yellow-legged Gull (Larus michahellis). We expected that the landfill closure would cause a strong dietary shift and the inadvertent poisoning a decrease in gull population size. As a long-lived species, we also anticipated adult survival to be buffered against the decrease in food availability but not against the inadvertent poisoning event. Stable isotope analysis confirmed the dietary shift towards marine resources after the disappearance of the landfill. Although the survival model was inconclusive, it did suggest that the perturbations had a negative effect on survival, which was followed by a recovery back to average values. Food limitation likely triggered dispersal to other populations, while poisoning may have increased mortality; these two processes were likely responsible for the large fall in population size that occurred after the two consecutive perturbations. Life-history theory suggests that perturbations may encourage species to halt existing breeding investment in order to ensure future survival. However, under strong perturbation pulses the resilience threshold might be surpassed and changes in population density can arise. Consecutive perturbations may effectively manage overabundant species.
\end{abstract}

Key words: adult survival; anthropogenic perturbation; Dragonera Island, Spain; food availability; Larus michahellis; pest; population size; predictable anthropogenic food subsidies; seabird; stable isotope analysis; Yellow-legged Gull.

\section{INTRODUCTION}

Human alterations of natural systems have triggered profound changes in ecosystem functioning and species communities (Vitousek et al. 1997). For instance, predictable anthropogenic food subsidies, such as landfill organic waste, have caused ecological and evolutionary changes at individual, population, community, and ecosystem levels (Oro et al. 2013 and references therein). Exploitation of subsidies alters not only dietary preferences but may increase body mass, body size, breeding performance, or survival on a wide range of species (Newsome et al. 2015). Subsidies are considered responsible for much of the demographic explosion of a wide range of so-called overabundant species, such as foxes, gulls, and rats (Duhem et al. 2008, Bino et al. 2010, Aplin et al. 2011). A large number of studies have tackled mitigation and management measures, such as direct culling aimed at reducing the

Manuscript received 6 November 2014; revised 20 March 2015; accepted 2 April 2015. Corresponding Editor: J. M. Marzluff.

${ }^{4}$ E-mail: anapayopayo@imedea.uib-csic.es ecological and social consequences of overabundant species (Bosch et al. 2000, Baker and Harris 2006, Merrill et al. 2006, Beasley et al. 2013). However, although these measures have been implemented worldwide, they have often turned out to be expensive and/or ineffective (Baker and Harris 2006, Oro and MartínezAbraín 2007, Warburton and Norton 2009). The main flaw is that management measures often aim to mitigate the consequences of the human alteration rather than avert the occurrence of the alteration itself. However, recent European Union (EU) environmental policies are beginning to target the causes rather than their symptoms. For example, the final modifications to the Landfill Waste Council Directive (LWCD; European Commission 2008, EU 2009) aim to put an end to openair landfill sites. In addition, these policies target a progressive reduction of predictable subsidies and are expected to trigger population control in some overabundant species. The exhaustive monitoring of the ecological processes ensuing after the closure of open-air landfill sites provides a unique perspective and understanding of the consequences to ecosystems of a forced reduction in supplementary feeding (Steigerwald et al. 
2015). Since seabirds are easily monitored and sensitive to changes in food availability, they provide a particularly good model for understanding the complexity and the efficacy of recent policy changes aimed at controlling overabundant species. For instance, changes caused by food limitation have been previously documented for seabird clutch size, egg volume, body size, breeding success, fecundity, adult survival, local recruitment, dispersal, and population size (Pons and Migot 1995, Harris et al. 1997, Oro and Pradel 2000, Oro and Furness 2002, Duhem et al. 2008).

Predictable food subsidies, together with the protection of suitable breeding areas in recent years, has led to an increase in large opportunistic gull populations (Duhem et al. 2008). Their growth has caused social annoyance as well as concerns for public health (Hatch 1996) and has trigged population control measures worldwide (Thomas 1972, Vidal et al. 1998, Bosch et al. 2000, Brooks and Lebreton 2001). For instance, Yellowlegged Gulls, Larus michahellis (YLG hereafter) in the Mediterranean basin have been subject to numerous culling programs aimed at controlling their numbers (the symptom) by targeting either a reduction in adult survival rates or breeding performance (Vidal et al. 1998, Brooks and Lebreton 2001, Duhem et al. 2008). Because seabirds are long-lived species, the reduction of adult survival is expected to have important population consequences (Sæther et al. 1996). However, direct culling had little effect on gull numbers because processes such as earlier recruitment or density-dependent higher fertility and immigration (Brooks and Lebreton 2001) were likely enhanced by high food availability, which might have boosted gulls' resilience to this type of perturbation (Oro and Martínez-Abraín 2007). Although food limitation has some impact on breeding performance, it is not expected to be particularly useful in controlling long-lived species; nevertheless, a long-term limitation of resources might be the key to controlling overabundant species by reducing recruitment (Oro and Martínez-Abraín 2007). When the two types of measures (food limitation and culling) are used together, their synergic or cumulative effects may lead to an important reduction in population size, although very little is known about the potential effects of linked management actions.

YLGs are large, colonial, and opportunistic seabirds distributed over the whole Mediterranean basin. YLG are known to exploit landfills to varying extents throughout their distribution range (Witt et al. 1981, Motis 1989, Bosch et al. 1994, Verdú del Campo et al. 1995, Ramos et al. 2009). Particularly, Ramos et al. (2011) assessed the importance of landfills on YLG in the western Mediterranean basin and demonstrated that landfill waste represents up to $60 \%$ of the diet of breeding YLG in our study colony. The recent explosion in YLG numbers has raised conservation concerns and several culling programs have been carried out in different locations. Despite these control measures, it is still the most abundant seabird in the Mediterranean (Zotier et al. 1999, Oro and Martínez-Abraín 2007).

We assessed the consequences on the ecology of YLG of two anthropogenic perturbations: (1) the closure of an open-air landfill site due to European Directives (EU 2009), which was estimated to represent half of its diet in terms of assimilated biomass (Ramos et al. 2011) and (2) the use of poison pellets in the study area to eradicate invasive pest, which caused indirect mortality in YLGs from primary (ingestion of pellets) and secondary (ingestion of poisoned rodents) poisoning (Mayol et al. 2012a). We investigated the changes in trophic ecology (dietary shift) and demographic parameters (population size and survival) of breeding YLGs that were attributable to the two consecutive anthropogenic perturbations. Life-history theory predicts that under limited food access, long-lived organisms will forego reproduction to avoid negatively affecting their future survival (Pugesek and Diem 1990, Oro et al. 1999). Thus, we expected that food limitation would trigger a dietary shift and differential resource exploitation, affecting breeding performance (Oro et al. 1995, Steigerwald et al. 2015) but not individual survival probability. Moreover, we expected that the inadvertent poisoning event would cause an increase in mortality rate due to the accidental poisoning of individuals. We expect that the combined effects of one action affecting reproductive performance and another affecting adult survival might trigger a decrease in population size. In addition, we expected our results to shed more light on the effects of consecutive perturbations and to provide a more comprehensive framework for superabundant species management.

\section{Methods \\ Study area and perturbations}

Data were collected at Dragonera Natural Reserve, a 300-ha island off the coast of Mallorca (Balearic archipelago, Spain, $39^{\circ} 35^{\prime} 02^{\prime \prime} \mathrm{N}, 02^{\circ} 19^{\prime} 17^{\prime \prime}$ E). This protected site hosts the largest-known YLG breeding colony in the archipelago (McMinn 2010). YLG nests can be found all over the island, with areas of gentle slope and low vegetation having higher density. The tourism industry on Mallorca $\left(\sim 10^{7}\right.$ tourists/year, with a population of $\sim 10^{6}$ residents) has increased waste production and its availability at a single landfill site for opportunistic feeders. This anthropogenic subsidy was responsible for the doubling of the YLG Balearic archipelago population between $1983(\sim 7500$ pairs) and 2000 ( $\sim 14000$ pairs; McMinn 2010). Local managers estimated the number of gulls foraging at the landfill ( $\sim 32 \mathrm{~km}$ from Dragonera) to range between 7300 and 15500 depending on the season and the year (TIRME 2003). Following European Directives (EU 2009), the open-air landfill was transformed into an incineration plant in winter 2009-2010. This transformation made waste virtually inaccessible to gulls. In mid-winter of the year after the transformation (January and February 
2011), an eradication campaign targeting the humanintroduced rats (Rattus rattus), mice (Mus musculus), and rabbits (Oryctolagus cuniculus) was carried out on Dragonera (Mayol et al. 2012b). This campaign involved the aerial application of Brodifacoum, a second generation anticoagulant whose main mechanism is blocking epoxy-reductose enzyme activity. Without generating bait shyness, this leads to lack of blood clotting factors, followed by hemorrhages, and eventually death (Hadler and Buckle 1992). In the weeks following the spread of the poison, $\sim 800$ YLG carcasses were found on the island (Servei de Protecció d'especies et al. 2011). This can be considered a minimum estimate given that the search was not exhaustive and the areas with dense vegetation and surrounding waters were not surveyed (Servei de Protecció d'especies et al. 2011).

\section{Trophic level and dietary shift}

Nitrogen $\left(\delta^{15} \mathrm{~N}\right)$, carbon $\left(\delta^{13} \mathrm{C}\right)$, and sulphur $\left(\delta^{34} \mathrm{~S}\right)$ isotopic ratios can be used in ecological studies to evaluate dietary shifts (Ramos et al. 2011), since analyses of individual feathers provide unique isotopic information for very specific spatiotemporal periods (Hobson 2008). We evaluated the nitrogen $\left(\delta^{15} \mathrm{~N}\right)$, carbon $\left(\delta^{13} \mathrm{C}\right)$, and sulphur $\left(\delta^{34} \mathrm{~S}\right)$ isotopic ratios of the first primary feather $(\mathrm{P} 1)$ on 68 unique breeding YLG individuals captured (see Methods: Local survival analysis and estimates of population abundance) in 2004 $(N=12), 2008(N=18), 2011(N=18)$, and $2013(N=20$; Table 2). P1 feathers were collected during the incubation period (April-May). Feathers were removed by cutting the feather quill, which causes no damage to the individuals. The P1 feather is replaced by molt at breeding sites, and its isotopic value is an indicator of the diet of the previous breeding season. Laboratory procedures for preparing and processing feather samples were carried out following Ramos et al. (2011). Feathers were washed in a $0.25 \mathrm{~mol} / \mathrm{L}$ sodium hydroxide solution, rinsed thoroughly in distilled water to remove any surface contaminants, dried in an oven at $60^{\circ} \mathrm{C}$ to constant mass, and ground to a fine powder in a freezer mill (Spex Certiprep 6750; Spex Industries, Metuchen, New Jersey, USA) operating at liquid nitrogen temperature. Subsamples of powdered material were weighed to the nearest microgram, placed in tin capsules, and crimped for combustion for $\mathrm{C}, \mathrm{N}$, and $\mathrm{S}$ isotope determination. Isotopic analyses were carried out at the Serveis Científico-Tècnics of the University of Barcelona (Spain) by means of a Thermo-Finnigan Flash 1112 (for N and C) and 1108 (for S; CE Elantech, Lakewood, New Jersey, USA) elemental analyzer coupled to a Delta-C isotope-ratio mass spectrometer via a CONFLOIII interface (Thermo Finnigan MAT, Bremen, Germany), and applying IAEA standards (IAEA CH6, IAEA CH7, and USGS 24 for C; IAEA $\mathrm{N} 1$, IAEA N2, and IAEA NO3 for $\mathrm{N}$; and IAEA-S1, IAEA-S2, and IAEA-S3 for S) every 12 samples to calibrate the system and compensate for any drift over time. Samples from 2004 were analyzed separately from 2008, 2011, and 2013 but the same instruments and standards were used. Precision and accuracy was $\leq 0.1 \%$ for $\delta^{13} \mathrm{C}$ measurements, $\leq 0.3 \%$ for $\delta^{15} \mathrm{~N}$, and $\leq 0.3 \%$ o for $\delta^{34} \mathrm{~S}$.

Results were expressed in delta $(\delta)$ notation (Bond and Hobson 2012). We used linear mixed models (LMM) to evaluate the effects of landfill closure, sex, and their interaction (Crawley 2007), with the year as the random effect (Zuur et al. 2009), to account for the effect of environmental variability on isotopic signatures. In addition, we estimated diet composition before and after landfill closure for males and females by applying Bayesian three-isotope $\left(\delta^{15} \mathrm{~N}, \delta^{13} \mathrm{C}\right.$, and $\delta^{34} \mathrm{~S}$ values), three-endpoint (marine, crops and terrestrial environments, and refuse sites) mixing models to the isotopic values (SIAR, stable isotope analysis in $\mathrm{R}$; Parnell et al. 2008). Ramos et al. (2011) recently evaluated the spatiotemporal variations the feeding ecology of YLG on the western Mediterranean region. Prey isotopic signatures were homogeneous among most of the localities studied, hence we included mean isotopic values $\left(\delta^{15} \mathrm{~N}, \delta^{13} \mathrm{C}\right.$, and $\left.\delta^{34} \mathrm{~S}\right)$ calculated in their study for the main food resources exploited by YLG in Dragonera (values from Table 5 in Ramos et al. 2011). Moreover, we used the consumer-discrimination factors provided by these authors.

\section{Local survival analysis and estimates of population abundance}

Breeding adults were trapped during the incubation period using a tent spring trap (see Steigerwald et al. 2015). We chose to trap individuals in accessible nests along the main south path of the island ( $4.5 \mathrm{~km}$ long) to increase re-sighting probabilities in the following years. In total, we trapped 206 YLG, which were marked using a Darvic plastic band (ProTouch, Saskatoon, Saskatchewan, Canada) with a unique alphanumeric code for subsequent individual identification from a distance using spotting scopes. Marking, re-sighting of live birds, and recovery of dead animals (99 and 12 cases, respectively) in March/April in 2007-2013 were used to build individual encounter histories and analyzed using multistate capture-mark-recapture recovery (CMRR) models to estimate survival, recapture, and recovery probabilities (Brownie and Hines 1993, Lebreton et al. 1999). Since all recoveries came from the colony site, CMRR models cannot distinguish mortality from permanent emigration to unobservable areas of the island. As a consequence, our estimates refer to apparent survival (Lebreton et al. 1992). We assessed the goodness-of-fit test (GOF) for the general model assuming that all parameters vary over time (JollyMove model; Brownie and Hines 1993, Pradel et al. 2003) using the software U-CARE 2.2.2 (Choquet et al. 2005, 2009). The global GOF test revealed no evidence of transient animals, meaning that there was no difference in the probability of being later reencountered 
TABLE 1. Results of the goodness-of-fit tests for the general capture-recapture-recovery multistate model for male and female Yellow-legged Gulls (Larus michahellis) on Dragonera Island, Spain.

\begin{tabular}{lrrrr}
\hline \hline \multicolumn{1}{c}{ Test } & $\chi^{2}$ & df & $P$ & $\hat{c}$ \\
\hline Males & & & & \\
3G.SR & 2.90 & 5 & 0.72 & 0.58 \\
3G.SM & 1.66 & 4 & 0.80 & 0.41 \\
M. Itec & 3.54 & 5 & 0.62 & 0.71 \\
M. Ltec & 0.37 & 3 & 0.95 & 0.12 \\
Global 3G & 4.55 & 9 & 0.87 & 0.51 \\
Global M & 3.91 & 8 & 0.87 & 0.49 \\
Females & & & & \\
3G.SR & 16.02 & 5 & 0.01 & 3.20 \\
3G.SM & 4.18 & 4 & 0.38 & 1.05 \\
M. Itec & 3.16 & 5 & 0.68 & 0.63 \\
M. Ltec & 5.62 & 4 & 0.23 & 1.41 \\
Global 3G & 20.20 & 9 & 0.02 & 2.25 \\
Global M & 8.82 & 9 & 0.45 & 0.98 \\
\hline
\end{tabular}

Notes: Test components are listed as in Pradel et al. (2003), where $3 \mathrm{G}$ tests for transients' presence and $\mathrm{M}$. tests for trap dependence. 3G.SR and 3G.SM test for among-individual homogeneity in survival; M.Itec and M.Ltec test for homogeneity in recapture process. Statistics are $\chi^{2}$, chi-square statistic; df, degrees of freedom; $\hat{c}$, inflation factor, i.e., $\chi^{2} / \mathrm{df}$.

between new and old individuals encountered at a given time, and that there were no trap-dependence effects (i.e., no difference in the probabilities of being reencountered in the different stages at $i+1$ between the animals in the same state at occasion $i$ whether or not encountered at this date). Thus, the general model adequately explained the data $\left(\chi^{2}=37.483, \mathrm{df}=35, P=\right.$ 0.356 ; Table 1). The GOF test for females indicated the presence of transients, but since the global GOF was not statistically significant we used a variance inflation factor, $\hat{c}=1.07$, to account for the remaining heterogeneity (Choquet et al. 2005, 2009). We identified a set of biological hypotheses (Fig. 1) and began by testing effects on a single parameter at a time (Lebreton et al. 1992). We considered the effect of year, sex, landfill closure, and the pest eradication campaign on local survival probability (Fig. 1). The landfill closure and pest eradication campaign effects were tested either as punctual or persistent depending on the temporal extent (short vs. long term, respectively) of the effect in the considered hypothesis (Fig. 1). Furthermore, we used the number of days spent searching for marked animals as a predictor of recapture probability and the effort (number of searching days) invested in searching for corpses by the Dragonera Natural Reserve team as a predictor of the recovery rate. We began by simplifying the structure of the recovery rate $(\lambda)$ from a general model $\left(\mathrm{E}_{0}\right)$, assuming all three parameters to be dependent on time and sex. We then modeled recapture $(p)$ and finally the survival parameter $(\varphi)$. Note that models' rank did not change when the model selection began with a different parameter (results not shown). Models were implemented using the program MARK 7.1 (White and Burnham 1999). Models were selected using the second order Akaike information criterion $\mathrm{AIC}_{\mathrm{c}}$ value and, in addition, deviances were scaled using the over-dispersion dispersion parameter $\left(\mathrm{QAIC}_{\mathrm{c}}\right.$; Burnham and Anderson 2002). We considered the model with lowest $\mathrm{AIC}_{\mathrm{c}}$ or $\mathrm{QAIC}_{\mathrm{c}}$ and those within two points of $\Delta \mathrm{AIC}_{\mathrm{c}}$ or $\triangle \mathrm{QAIC}_{\mathrm{c}}$ (the difference in $\mathrm{AIC}_{\mathrm{c}}$ and $\mathrm{QAIC}_{\mathrm{c}}$ values, respectively) to be equivalent, and we used these models to produce final model-averaged parameter estimates (mean \pm SE; Burnham and Anderson 2002). In this way, we included the effects of parameters obtained from separate models and accounted for model selection uncertainty (Burnham and Anderson 1998).

Each year, we estimated nest density in a 0.32 -ha area ( $0.11 \%$ of Dragonera Island surface) with gentle slope and low vegetation as proxy of population size and for assessing its fluctuations over the study period. We assumed that despite that nest density might not be homogeneous within the island, the relative change in its value was a good indicator of population changes, as the surface occupied by the colony remained invariant. Five to nine observers walked the delimited area forming a transect line with a distance of $\sim 3-5 \mathrm{~m}$ between each

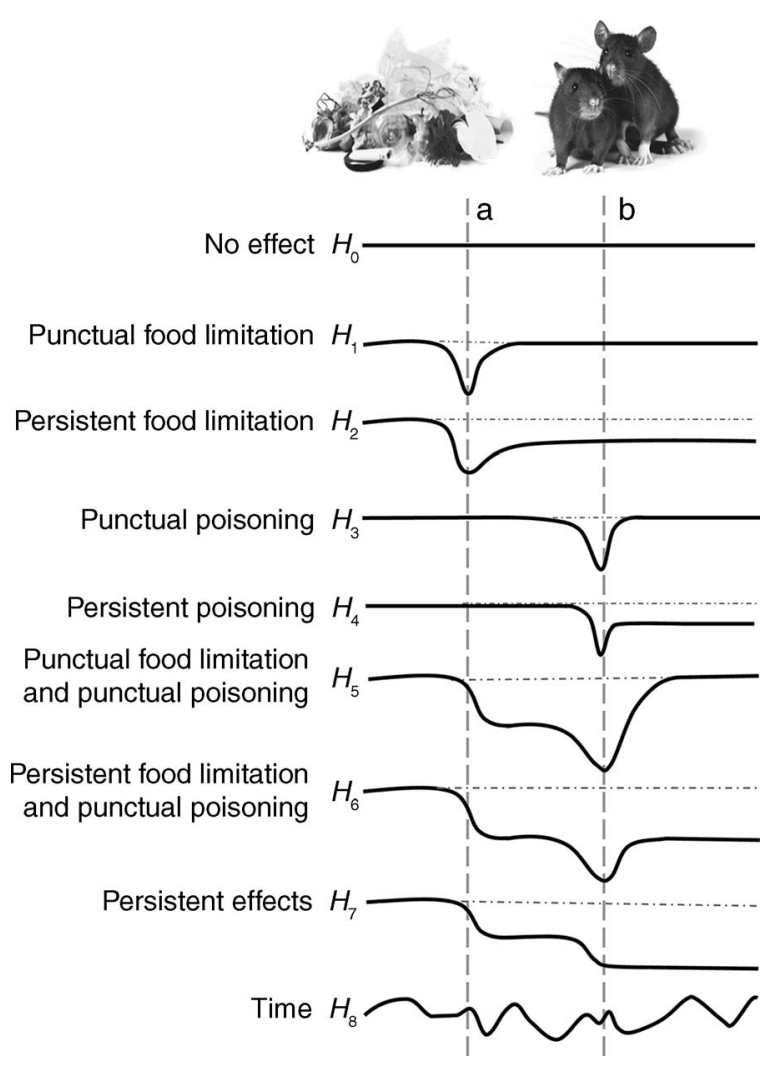

FIG. 1. Survival probability $(\Phi)$ shows qualitative representation under different biological hypotheses. Dashed lines a and b represent the landfill closure and the eradication campaign, respectively. Survival hypotheses are numbered in growing complexity and assigned to the analogous model on Table 1 (model number in parentheses): $H_{0}\left(\mathrm{M}_{0}\right), H_{1}\left(\mathrm{M}_{1}\right), H_{2}\left(\mathrm{M}_{2}\right), H_{3}$ $\left(\mathrm{M}_{3}\right), H_{4}\left(\mathrm{M}_{4}\right), H_{5}\left(\mathrm{M}_{5}\right), H_{6}\left(\mathrm{M}_{6}\right), H_{7}\left(\mathrm{M}_{7}\right)$, and $H_{8}\left(\mathrm{M}_{8}\right)$. 
TABLE 2. Values (mean \pm SE) of nitrogen $\left(\delta^{15} \mathrm{~N}\right)$, carbon $\left(\delta^{13} \mathrm{C}\right)$, and sulphur $\left(\delta^{34} \mathrm{~S}\right)$ stable isotope signatures of male and female Yellow-legged Gulls at Dragonera Island before (2004 and 2008) and after (2011 and 2013) the landfill closure.

\begin{tabular}{lrr}
\hline \hline Variable, by sex & \multicolumn{1}{c}{ Before $(\%)$} & \multicolumn{1}{c}{ After $(\%)$} \\
\hline Male & & \\
$\delta^{15} \mathrm{~N}$ & $10.69 \pm 0.12$ & $11.11 \pm 0.29$ \\
$\delta^{13} \mathrm{C}$ & $-19.91 \pm 0.10$ & $-19.64 \pm 0.27$ \\
$\delta^{34} \mathrm{~S}$ & $10.85 \pm 0.62$ & $13.95 \pm 0.63$ \\
Female & & \\
$\delta^{15} \mathrm{~N}$ & $10.50 \pm 0.18$ & $10.91 \pm 0.22$ \\
$\delta^{13} \mathrm{C}$ & $-20.13 \pm 0.21$ & $-19.94 \pm 0.18$ \\
$\delta^{34} \mathrm{~S}$ & $11.48 \pm 0.71$ & $14.51 \pm 0.60$ \\
\hline
\end{tabular}

other and marking all encountered nests. Observers shuffled position within the line and surveyed the transect a second time to recapture marked nests and count new ones. The number of nests in the area was then estimated by the Lincoln-Petersen estimator (Williams et al. 2001, Seber 2002). We used the delta method (Morgan 2000) to approximate the variance of the mean before and after the landfill closure and the pest eradication campaign. We then assessed if there was a population change after the events with a $Z$ test (Zar 2010).

\section{Results}

\section{Trophic level and dietary shift}

We analyzed nitrogen $\left(\delta^{15} \mathrm{~N}\right)$, carbon $\left(\delta^{13} \mathrm{C}\right)$, and sulphur $\left(\delta^{34} \mathrm{~S}\right)$ isotopic ratios before and after the landfill closure (Table 2). The model selection procedure showed no significant changes in $\delta^{13} \mathrm{C}$ before and after the landfill closure (Table 3 , model $\mathrm{M}_{1}$; see Appendix: Table A1 for estimates). The landfill effect was not retained in the analysis of $\delta^{15} \mathrm{~N}$ (Table 3, $\mathrm{M}_{1}$; Appendix: Table A1 for estimates), although that effect was present in an equivalent model $\left(\Delta \mathrm{AIC}_{\mathrm{c}}=0.36\right.$ for model $\mathrm{M}_{2}$, Table 3; Appendix: Table A1 for estimates). All retained models for $\delta^{34} \mathrm{~S}$ (Table $3, \mathrm{M}_{2}, \mathrm{M}_{4}$, and $\mathrm{M}_{5}$; see Appendix: Table A1 for estimates) included the landfill effect as important, giving larger $\delta^{34} \mathrm{~S}$ values after landfill closure. Males and females had the same isotopic signature, however a sex effect was accounted for in two of the best three models of $\delta^{34} \mathrm{~S}$ (Table 2, $\mathrm{M}_{4}$ and $\mathrm{M}_{5}$; see Appendix: Table A1 for estimates), indicating a small (not statistically significant) difference in male and female diet. Model results for isotopic contents (Table 3, Fig. 2), together with the estimated percentage of diet diversity indicated by the SIAR analysis (Fig. 3), revealed changes in resource use after the landfill closure: the marine content of the diet increased while refuse diet content decreased, as expected.

\section{Local survival and population size}

The model selection procedure resulted in five models having more than $10 \%$ of the $\mathrm{QAIC}_{\mathrm{c}}$ weight and occurring within 1 point of $\mathrm{QAIC}_{\mathrm{c}}$ value (Table 4 ), impairing conclusions on the statistical significance of each single effect. This uncertainty was probably due to the complexity of the model used to join two types of information (recoveries and recaptures) and the relatively small data set available. Nevertheless, modelaveraging techniques took this uncertainty into account and delivered weighted estimates of the parameters of

TABLE 3. Table summarizing the model selection for isotope signatures of Yellow-legged Gulls breeding on Dragonera Island, Spain.

\begin{tabular}{|c|c|c|c|c|c|}
\hline $\begin{array}{l}\text { Isotope signature } \\
\text { and model }\end{array}$ & Model notation & $\mathrm{np}$ & $\mathrm{AIC}_{\mathrm{c}}$ & $\Delta \mathrm{AIC}_{\mathrm{c}}$ & $w$ \\
\hline \multicolumn{6}{|l|}{$\delta^{13} \mathrm{C}$} \\
\hline $\mathbf{M}_{1}$ & $\delta^{13} \mathrm{C}$ & 1 & 170.40 & 0.00 & 0.58 \\
\hline $\mathrm{M}_{2}$ & $\delta^{13} \mathrm{C}_{\text {LANDFILL }}$ & 2 & 173.20 & 2.75 & 0.15 \\
\hline $\mathrm{M}_{3}$ & $\delta^{13} \mathrm{C}_{\mathrm{SEX}}$ & 2 & 172.60 & 2.19 & 0.20 \\
\hline $\mathrm{M}_{4}$ & $\delta^{13} C_{\text {LANDFILL }+ \text { SEX }}$ & 3 & 175.10 & 4.65 & 0.06 \\
\hline $\mathrm{M}_{5}$ & $\delta^{13} C_{\text {LANDFILL }+ \text { SEX + LANDFILL } \times \text { SEX }}$ & 4 & 177.50 & 7.01 & 0.02 \\
\hline \multicolumn{6}{|l|}{$\delta^{15} \mathrm{~N}$} \\
\hline $\mathbf{M}_{1}$ & $\delta^{15} \mathbf{N}$ & 1 & 187.40 & 0.00 & 0.43 \\
\hline $\mathrm{M}_{2}$ & $\delta^{15} \mathrm{~N}_{\text {LANDFILL }}$ & 2 & 187.70 & 0.36 & 0.36 \\
\hline $\mathrm{M}_{3}$ & $\delta^{15} \mathrm{~N}_{\mathrm{SEX}}$ & 2 & 190.40 & 2.98 & 0.10 \\
\hline $\mathrm{M}_{4}$ & $\delta^{15} \mathrm{~N}_{\text {LANDFILL+SEX }}$ & 3 & 190.50 & 3.11 & 0.09 \\
\hline $\mathrm{M}_{5}$ & $\delta^{15} \mathrm{~N}_{\text {LANDFILL }+ \text { SEX + LANDFILL } \times \text { SEX }}$ & 4 & 192.60 & 5.27 & 0.03 \\
\hline \multicolumn{6}{|c|}{ 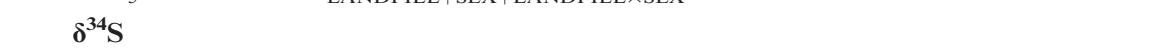 } \\
\hline $\mathbf{M}_{2}$ & $\delta^{34} \mathrm{~S}_{\text {LANDFILL }}$ & 2 & 321.70 & 0.00 & 0.33 \\
\hline $\mathrm{M}_{4}$ & $\delta^{34} \mathrm{~S}_{\text {LANDFILL }+ \text { SEX }}$ & 3 & 322.00 & 0.35 & 0.28 \\
\hline $\mathrm{M}_{5}$ & $\delta^{34} \mathrm{~S}_{\text {LANDFILL }+ \text { SEX }+ \text { LANDFILL } \times \text { SEX }}$ & 4 & 322.10 & 0.39 & 0.28 \\
\hline $\mathrm{M}_{1}$ & $\delta^{34} \mathrm{~S}$ & 1 & 325.20 & 3.54 & 0.06 \\
\hline $\mathrm{M}_{3}$ & $\delta^{34} \mathrm{~S}_{\mathrm{SEX}}$ & 2 & 325.40 & 3.69 & 0.05 \\
\hline
\end{tabular}

Notes: The best model for each isotope is shown in bold. All models include year as random factor. Notations are LANDFILL, landfill closure effect; SEX, sex effect; +, additive effect; $\times$, interaction effect; $\mathrm{np}$, number of parameters; $\mathrm{AIC}_{\mathrm{c}}$, corrected Akaike's information criterion; $\Delta \mathrm{AIC}_{\mathrm{c}}, \mathrm{AIC}_{\mathrm{c}}$ difference with the best model; $w$, Akaike weight. 
interest according to the model $\mathrm{QAIC}_{\mathrm{c}}$ value. The model with the lowest $\mathrm{QAIC}_{\mathrm{c}}$ value (model $\mathrm{M}_{0}$, Table 4) indicated a constant survival, i.e., independent of sex and the perturbations or the years considered. Averaged estimates were calculated for models $\mathrm{M}_{0-3}$ and $\mathrm{M}_{5}$, which were within $2 \mathrm{QAIC}_{\mathrm{c}}$ points of the one with the lowest value $\left(\mathrm{M}_{0}\right)$. All these models included the effect of food limitation and averaged estimates suggest that the closure of the landfill caused an $8 \%$ drop in survival (from $0.71 \pm 0.07$ in 2009 to $0.63 \pm 0.07$ in 2010). Similarly, the averaged estimates immediately after the pest eradication program indicated an additional $2 \%$ drop in apparent survival (from $0.63 \pm 0.07$ in 2010 to $0.61 \pm 0.11$ in 2011). The two synergic perturbations caused a $10 \%$ drop in survival probability when compared to the value before the landfill closure.

Nest survey data clearly showed a decrease in size of the nesting population after the two perturbations. The number of nests in the surveyed area first decreased by $37 \%$ after the landfill closure (from $92.13 \pm 4.01$ in 2009 to $58.05 \pm 5.71$ in 2010 ) and had an additional drop of $65.99 \%$ after the pest eradication campaign (from $58.05 \pm$ 5.71 in 2010 to $20.19 \pm 2.30$ in 2010; Fig. 4). Both perturbations caused a statistically significant change in nesting population size $(Z=13.78, P<0.00001$ and $Z=$ 17.19, $P<0.00001$ for landfill closure and poisoning campaign, respectively). The two synergic perturbations caused a $78 \%$ drop in nesting population size when compared to the value before the landfill closure (Fig. 4).

We found no significant differences in either survival between males and females, or over time (Table $4, \mathrm{M}_{8-13}$ ). The search for carcasses and the sampling effort (Table 4, $\mathrm{M}_{9}$ and $\mathrm{M}_{12}$, respectively) well predicted recovery and recapture probabilities, respectively. Average recapture probabilities ranged between $0.24(\mathrm{SE}=0.06)$ and 0.47 $(\mathrm{SE}=0.07$; Fig. $5 \mathrm{~b})$, while recovery probabilities were constant $(0.07 \pm 0.03)$, except for a $0.18(\mathrm{SE}=0.09)$ increase in 2010 when a specific search for carcasses was conducted (Fig. 5c).

\section{DiscusSION}

We assessed trophic and demographic changes in YLG after two consecutive anthropogenic perturbations, namely a food reduction after the closure of an open-air landfill and the accidental poisoning due to a campaign targeting the eradication of invasive mammals. Extensive research has been performed on the effects of predictable anthropogenic food sources across taxa (see reviews in Oro et al. 2013, Newsome et al. 2015). Specifically, several studies on gulls have assessed the effects of food availability on several parameters such as diet (Ramos et al. 2011), survival (Oro et al. 1999), and population size (Oro et al. 1999, 2004, Duhem et al. 2008). These studies recorded that a decrease in the availability of food subsidies caused changes in resource exploitation and increased dispersal, whereas survival remained constant. However, none of
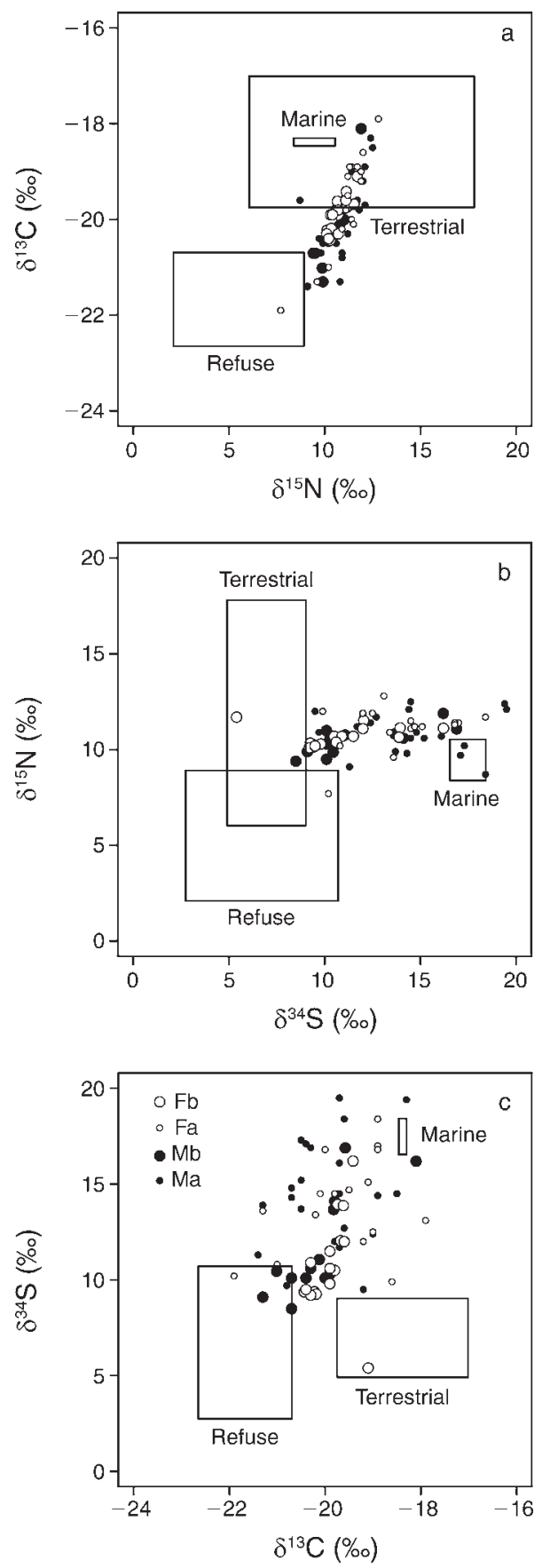

FIG. 2. Isotope signatures of (a) $\delta^{13} \mathrm{C}$, (b) $\delta^{34} \mathrm{~S}$, and (c) $\delta^{15} \mathrm{~N}$ of male (solid circles) and female (open circles) Yellow-legged Gulls (Larus michahellis) breeding on Dragonera Island, Spain, before (large circles) and after (small circles) the landfill closure. Tissue from first primary feathers. Rectangles represent mean \pm 1.96 SE isotopic signature from marine, crops and terrestrial, and waste food sources, as calculated by Ramos et al. (2011).

these studies analyzed all these parameters simultaneously, nor did they evaluate the consequences of the combined effect of food limitation and additive mortality on population dynamics. 


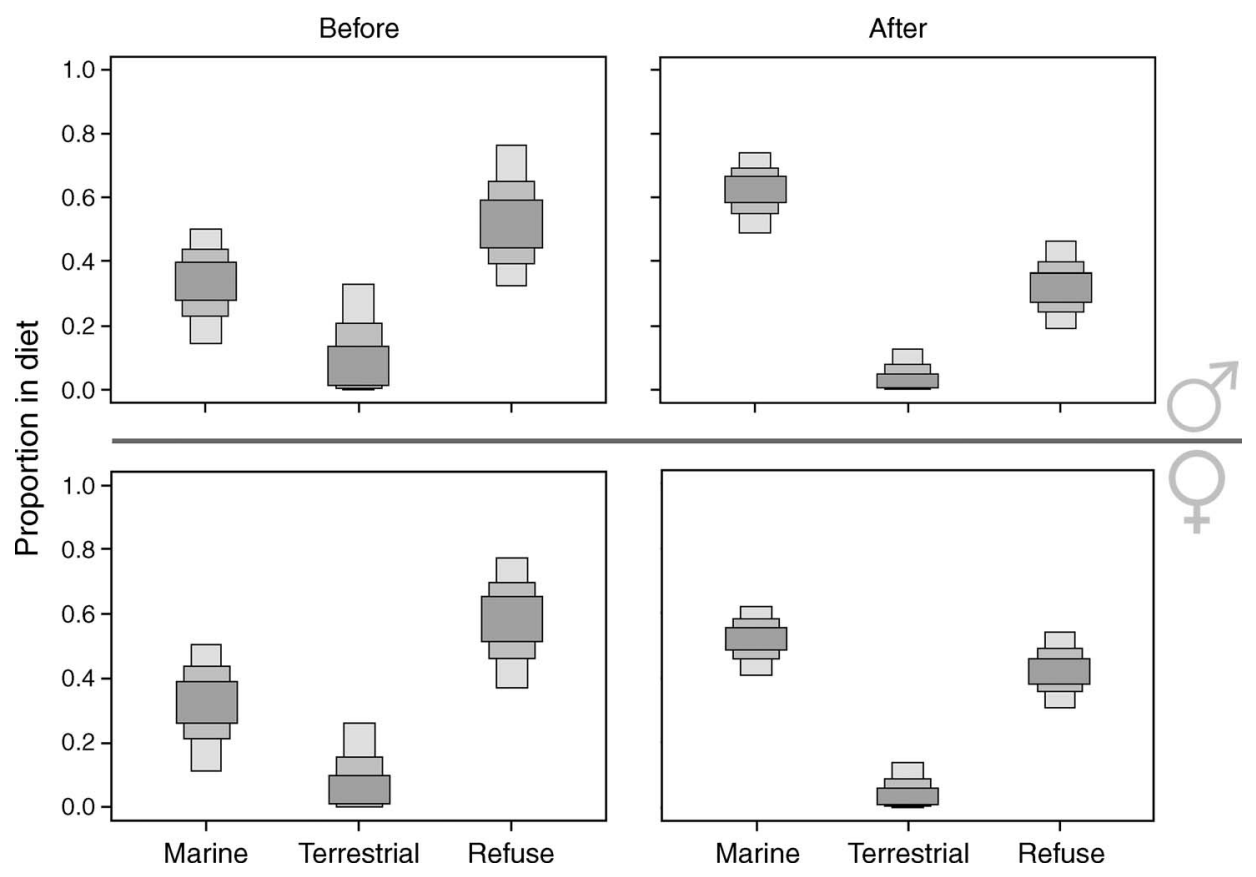

FIG. 3. Diet estimates of marine, terrestrial, and waste resources (true proportions and their Bayesian credibility intervals including $50 \%, 75 \%$, and $95 \%$ of the posterior distributions) estimated by stable isotope analysis in $\mathrm{R}$ mixing modeling based on C, $\mathrm{N}$, and $\mathrm{S}$ isotopic signatures from the first primary (P1) feathers of Yellow-legged Gulls from Dragonera Island (left) before and (right) after landfill closure in males (upper panels) and females (lower panels). Sample sizes are $N=23$ males before landfill closure, $N=9$ males after closure, $N=25$ females before, and $N=15$ females after.

Predictable anthropogenic food can be a low-quality resource (the so-called junk-food; see Pierotti and Annett 1991, Annett and Pierotti 1999, Grémillet et al. 2008, Genovart et al. 2010), but gulls appear to adjust their diet in accordance with the availability, rather than with the quality, of foraging resources except when feeding chicks (Pons 1992, Pedrocchi et al. 1996, Oro et al. 2004). During the last few decades, landfills have provided YLG with a vast food surplus, leading to higher carrying capacity and rapid population growth (Duhem et al. 2008). It is likely that when access to this food was restrained, gulls were forced to exploit more energetically demanding and less predictable (unless obtained from fishery discards) marine prey (Bartumeus et al. 2010). We present partial evidence of this dietary shift toward marine resources in YLG trophic behavior

TABLE 4. Modelling of survival $(\Phi)$, recapture $(\mathrm{P})$, and recovery $(\lambda)$ probabilities of Yellow-legged Gulls on Dragonera Island, Spain.

\begin{tabular}{|c|c|c|c|c|c|}
\hline Model & Model notation & $\mathrm{np}$ & $\mathrm{QAIC}_{\mathrm{c}}$ & $\Delta \mathrm{QAIC}_{\mathrm{c}}$ & $w$ \\
\hline $\mathbf{M}_{\mathbf{0}}$ & Ф. $\mathbf{P}_{\mathbf{E}} \lambda_{\mathrm{B}}$ & 5 & 579.26 & 0.00 & 0.23 \\
\hline $\mathrm{M}_{1}$ & $\Phi_{\text {LANDFILL }} ! \mathrm{P}_{\mathrm{E}} \lambda_{\mathrm{B}}$ & 6 & 579.76 & 0.50 & 0.18 \\
\hline $\mathrm{M}_{3}$ & $\Phi_{\text {PEST! }} \mathrm{P}_{\mathrm{E}} \lambda_{\mathrm{B}}$ & 6 & 580.17 & 0.91 & 0.15 \\
\hline $\mathrm{M}_{2}$ & $\Phi_{\text {LANDFILL } \infty} \mathrm{P}_{\mathrm{E}} \lambda_{\mathrm{B}}$ & 6 & 580.18 & 0.92 & 0.15 \\
\hline $\mathrm{M}_{5}$ & $\Phi_{\text {LANDFILL!+PEST! }} \mathrm{P}_{\mathrm{E}} \lambda_{\mathrm{B}}$ & 7 & 580.21 & 0.95 & 0.14 \\
\hline$M_{6}$ & $\Phi_{\text {LANDFILL } \infty+\text { PEST }} ! \mathrm{P}_{\mathrm{E}} \lambda_{\mathrm{B}}$ & 7 & 581.82 & 2.56 & 0.06 \\
\hline $\mathrm{M}_{7}$ & $\Phi_{\text {LANDFILL } \infty+\text { PEST } \infty} \mathrm{P}_{\mathrm{E}} \lambda_{\mathrm{B}}$ & 8 & 582.34 & 3.08 & 0.05 \\
\hline $\mathrm{M}_{4}$ & $\Phi_{\mathrm{PEST} \infty} \mathrm{P}_{\mathrm{E}} \lambda_{\mathrm{B}}$ & 6 & 584.38 & 5.11 & 0.02 \\
\hline $\mathrm{M}_{8}$ & $\Phi_{\mathrm{T}} \mathrm{P}_{\mathrm{E}} \lambda_{\mathrm{B}}$ & 10 & 584.88 & 5.62 & 0.01 \\
\hline $\mathrm{M}_{9}$ & $\Phi_{\mathrm{T}+\mathrm{SEX}} \mathrm{P}_{\mathrm{E}} \lambda_{\mathrm{B}}$ & 15 & 592.48 & 13.21 & 0.00 \\
\hline $\mathrm{M}_{10}$ & $\Phi_{\mathrm{T}+\mathrm{SEX}} \mathrm{P}_{\mathrm{T}} \lambda_{\mathrm{B}}$ & 20 & 595.99 & 16.73 & 0.00 \\
\hline $\mathrm{M}_{11}$ & $\Phi_{\mathrm{T}+\mathrm{SEX}} \mathrm{P}_{\mathrm{T}+\mathrm{SEX}} \lambda_{\mathrm{B}}$ & 26 & 608.36 & 29.10 & 0.00 \\
\hline $\mathrm{M}_{12}$ & $\Phi_{\mathrm{T}+\mathrm{SEX}} \mathrm{P}_{\mathrm{T}+\mathrm{SEX}} \lambda_{\mathrm{B}+\mathrm{SEX}}$ & 28 & 612.4 & 33.14 & 0.00 \\
\hline $\mathrm{M}_{13}$ & $\Phi_{\mathrm{T}+\mathrm{SEX}} \mathrm{P}_{\mathrm{T}+\mathrm{SEX}} \lambda_{\mathrm{T}+\mathrm{SEX}}$ & 32 & 617.66 & 38.40 & 0.00 \\
\hline
\end{tabular}

Notes: The best model is shown in bold. Model subscripts refer to hypotheses in Fig. 1 . Notations are LANDFILL, landfill effect; T, year effect; B, recovery effort; E, recapture effort; PEST, pest eradication effect; !, punctual; $\infty$, persistent; ', no effect; + , additional effect; np, number of estimable parameters in the model; QAIC $\mathrm{C}_{\mathrm{c}}$, Akaike's information criterion corrected for sample size, number of parameters, and over-dispersion; $\triangle \mathrm{QAIC}_{\mathrm{c}}, \mathrm{QAIC}_{\mathrm{c}}$ difference with the best model; $w$, weight of the model. 
following a landfill closure. Since we were only interested in changes occurring at a population level, we did not account for the differences between individual's trophic behavior (Navarro et al. 2010). The evidence was clear in sulphur isotope signature: YLG exploited significantly more marine resources after the landfill closure; however, we failed to detect a change in carbon isotope signature. The threshold to detect a change in sulphur isotope signatures lies around 10\% while it is $3 \%$ for carbon isotope signatures (see Fig. 2 and mean isotopic values in Ramos et al. 2011). We attribute our non-statistically significant difference in carbon isotope signatures to a lack of statistical power, and hence cannot ascertain nor deny a possible effect. However, other YLG colonies have been observed to follow the same pattern (see Arizaga et al. 2013). The use of $\delta^{34} \mathrm{~S}$ is commonly used to characterize the effect of marine food sources on various species (Lott et al. 2003, Natsumeda et al. 2015). Moreover, Moreno et al. (2010) demonstrated the potential of using $\delta^{34} \mathrm{~S}$ alone to distinguish not only between terrestrial and marine prey, but also between different marine prey species. Pedro et al. (2013) showed that exploitation of waste food by large, opportunistic gulls is a relatively new strategy that appeared less than 100 years ago. It is therefore not surprising that YLG from Dragonera were able to increase their consumption of marine and other terrestrial prey after food from landfill waste became unavailable. Moreover, other studies have also demonstrated a reduction in YLG waste consumption in this study area after the landfill closure (Ramos et al. 2011). It therefore seems reasonable to conclude that a diet change towards a marine diet occurred as a result of the landfill closure.

Low food availability is also known to increase intraspecific competition and reduce the contribution of each individual to the next generation (Begon et al. 1996). Breeding seabirds suffering from food limitation face survival vs. reproduction trade-offs, and they are expected to forego current reproduction to guarantee adult survival prospects in order to increase the odds of future generations living under favorable conditions (Pons 1992, Pons and Migot 1995, Oro 1999, SanzAguilar et al. 2008). Previous studies on gulls found severe impacts on breeding performance under different levels of food availability (Pons 1992, Pons and Migot 1995, Oro 1996). Particularly, our colony suffered a significant decrease in breeding performance (clutch size and egg volume) after landfill closure (Steigerwald et al. 2015). Moreover, Steigerwald et al. (2015) suggested that a dietary switch, which we confirmed, might not have been sufficient to fully cover the energy requirements of the local population. Foregoing reproduction to guarantee adult survival acts as a buffer mechanism against environmental variability and allows animals to cope with moderate environmental perturbations. Nevertheless, when food is in very short supply it can even affect body mass and local adult survival in long-lived

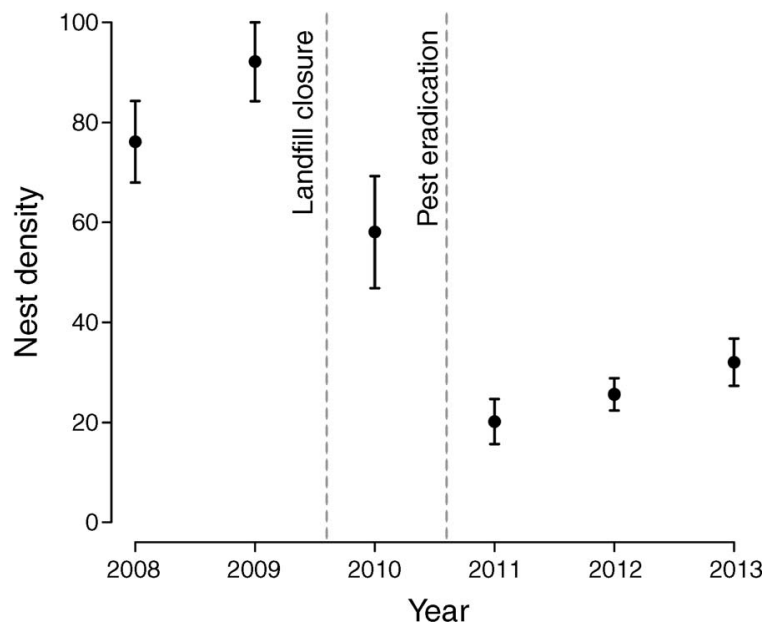

FIG. 4. Changes in nest density as a proxy of population size (mean $\pm 1.96 \mathrm{SE}$ ) of Yellow-legged Gulls breeding on Dragonera Island, Spain. Dashed lines indicate landfill closure and pest eradication campaign dates.

seabirds (Oro and Furness 2002). This appears to be the case for our population, given the recorded drop in YLG body condition (Steigerwald et al. 2015) along with a slight decrease in local survival rates after landfill closure. Gulls usually form spatially structured populations (Oro et al. 2003) and given that previous studies have shown that dispersal occurs following environmental perturbations (Oro et al. 2004, Fernández-Chacón et al. 2013), we suggest that food limitation has triggered not only mortality but also permanent emigration (through breeding dispersal) to neighboring populations (Bosch 2000, Oro 2003).

These findings agree with previous work on other seabird species (Oro 1999, Oro et al. 2004, Duhem et al. 2008), which found a close correlation between anthropogenic food availability and colony size. Our work suggests that the decrease in food availability caused a dietary shift towards marine resources. The dietary shift was followed by a partial reduction in breeding performance (Steigerwald et al. 2015), leading to an increase in mortality and dispersal. Finally, the cumulative effects of poisoning magnified an already severe decrease in population size through real adult mortality. Despite that many individuals might have died or emigrated from the study area, those remaining exhibited similar survival compared to pre-perturbation values. Another possible explanation for why population size and survival follow different response patterns after these perturbations is that poisoning was intended to cause nonselective mortality across the whole population, thus also affecting non-breeders and immature gulls, but our survival estimates came only from breeding adults. Alternatively, the termination of the waste food surplus might have decreased the carrying capacity of the system and the population size could therefore have declined to match this new population 

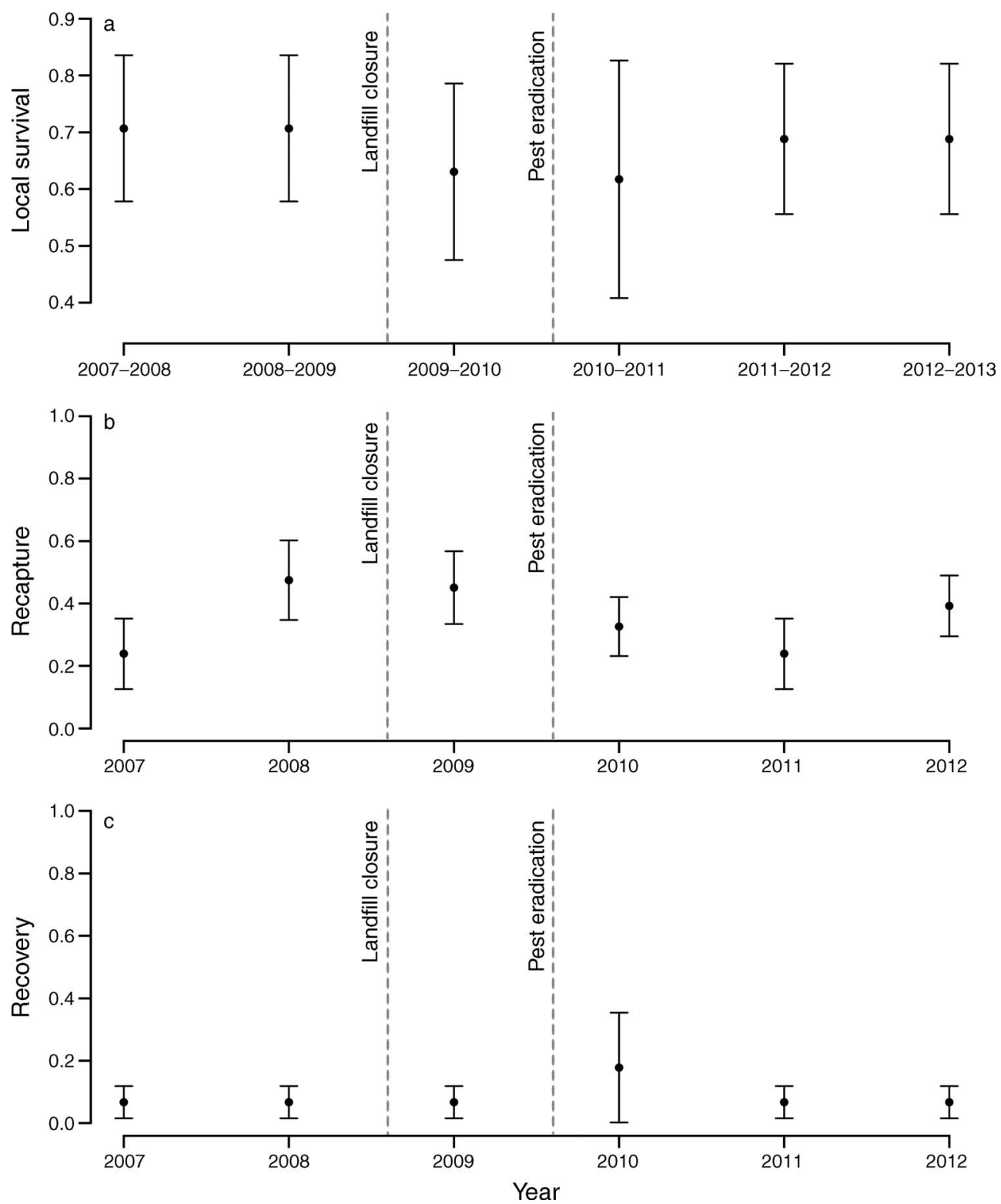

FIG. 5. Temporal variability in the estimated probabilities (mean and 95\% CI) of (a) local survival, (b) recapture, and (c) recovery $(95 \%$ CI) of Yellow-legged Gulls on Dragonera Island in 2007-2013 as estimated by the model-averaging of the five best equivalent models with $\triangle \mathrm{QAIC}_{\mathrm{c}}<2\left(\mathrm{QAIC}_{\mathrm{c}}\right.$, Akaike's information criterion corrected for sample size, number of parameters, and over-dispersion; $\triangle \mathrm{QAIC}_{\mathrm{c}}, \mathrm{QAIC}_{\mathrm{c}}$ difference from the best model).

ceiling, while also influenced by the additive mortality from poisoning. We predict that population size will slowly increase in the coming years until it stabilizes at a new demographic equilibrium, however it will not reach the levels recorded before the two perturbations (Bosch et al. 2000).

\section{Implications for the management of overabundant species}

The food limitation and the mammal eradication campaign through poisoning were not specifically intended for the management of YLG populations. However, these actions allowed us to explore the implications of the combined effect in controlling of consecutive actions on the management of a so-called overabundant species. Many populations of overabundant species of birds and mammals are subject to extensive management programs designed to control their numbers (Mate et al. 1998, Anderson and Devlin 1999, Twigg and Kent Williams 1999, Bosch et al. 2000). These actions mainly aim to either reduce breeding success (Thomas 1972, Merrill et al. 2006) or to eliminate adults by culling (Bosch et al. 2000, Baker and Harris 2006). Such management is expensive and ineffective in the long term if applied in isolation (Baker 
and Harris 2006, Merrill et al. 2006, Oro and MartínezAbraín 2007). We present evidence of how these two consecutively occurring perturbations have been extremely effective in reducing the population density of a generalist opportunistic bird, which has not recovered in the three years following these events. Under strong perturbation pulses (Martínez-Abraín et al. 2012) or intense environmental variability (Harding et al. 2011), the density-dependent responses of demographic parameters appear insufficient to buffer population changes. Although an isolated perturbation, such as poisoning, seemed to have an important short-term effect, it is reasonable to believe that it was the closure of the landfill site that led to a permanent decrease in the carrying capacity of the system and hence a long-lasting reduction in population numbers, as previously suggested by Oro and Martínez-Abraín (2007). Cumulative effects of consecutive perturbations are likely to become a useful tool in the control of overabundant populations. Nevertheless, despite the potential that these results have for the implementation of more effective management actions of overabundant species, caution must be taken because their long-term consequences are still unknown.

\section{ACKNOWLEDGMENTS}

We thank Nathalie Chardon for editing and correction of the paper. We also thank the PEG staff at IMEDEA for their help with the fieldwork. J. Muntaner and SKUA provided rings and information on Yellow-legged Gull. Thanks are also due to Marti Mayol and the staff of the Dragonera Natural Reserve for their help. Mike Lockwood improved the English. The comments of the editor and two anonymous reviewers helped to improve the quality of the manuscript. Permits were provided by the OAPN (Spanish Ministry of the Environment) and Balearic Regional Government. A. Payo-Payo was supported by a fellowship from the Spanish Ministry of Education (ref. FPU2012-000869). Funds were also partially provided by the Balearic Government (FEDER Program) and the Spanish Ministry of Economy (ref. CGL2013-42203-R).

\section{Literature Cited}

Anderson, J. G. T., and C. M. Devlin. 1999. Restoration of a multi-species seabird colony. Biological Conservation 90:175-181.

Annett, C. A., and R. Pierotti. 1999. Long-term reproductive output in Western Gulls: consequences of alternate tactics in diet choice. Ecology 80:288-297.

Aplin, K. P., et al. 2011. Multiple geographic origins of commensalism and complex dispersal history of black rats. PLoS ONE 6:e26357.

Arizaga, J., L. Jover, A. Aldalur, J. F. Cuadrado, A. Herrero, and C. Sanpera. 2013. Trophic ecology of a resident Yellowlegged Gull (Larus michahellis) population in the Bay of Biscay. Marine Environmental Research 87-88:19-25.

Baker, P. J., and S. Harris. 2006. Does culling reduce fox (Vulpes vulpes) density in commercial forests in Wales, UK? European Journal of Wildlife Research 52:99-108.

Bartumeus, F., L. Giuggioli, M. Louzao, V. Bretagnolle, D. Oro, and S. A. Levin. 2010. Fishery discards impact on seabird movement patterns at regional scales. Current Biology 20:215-222.

Beasley, J. C., Z. H. Olson, W. S. Beatty, G. Dharmarajan, and O. E. Rhodes, Jr. 2013. Effects of culling on mesopredator population dynamics. PLoS ONE 8:e58982.
Begon, M., M. Mortimer, and D. J. Thompson. 1996. Population ecology: a unified study of animals and plants. Blackwell Science, Malden, Massachusetts, USA.

Bino, G., A. Dolev, D. Yosha, A. Guter, R. King, D. Saltz, and S. Kark. 2010. Abrupt spatial and numerical responses of overabundant foxes to a reduction in anthropogenic resources. Journal of Applied Ecology 47:1262-1271.

Bond, A. L., and K. A. Hobson. 2012. Reporting stable-isotope ratios in ecology: recommended terminology, guidelines and best practices. Waterbirds 35:324-331.

Bosch, M. 2000. Ecology of the Yellow-legged Gull Larus cachinnans in the Medes Islands. Universidad Barcelona.

Bosch, M., D. Oro, F. J. Cantos, and M. Zabala. 2000. Shortterm effects of culling on the ecology and population dynamics of the Yellow-legged Gull. Journal of Applied Ecology 37:369-385.

Bosch, M., D. Oro, and X. Ruiz. 1994. Dependence of Yellowlegged Gulls (Larus cachinnans) on food from human activity in two western Mediterranean colonies. Avoceta 18:135-139.

Brooks, E. N., and J.-D. Lebreton. 2001. Optimizing removals to control a metapopulation: application to the Yellowlegged Herring Gull (Larus cachinnans). Ecological Modelling 136:269-284.

Brownie, C., and J. E. Hines. 1993. Capture-recapture studies for multiple strata including non-Markovian transitions. Biometrics 49:1173-1187.

Burnham, K. P., and D. R. Anderson. 1998. Model selection and inference: a practical information-theoretic approach. Springer-Verlag, New York, New York, USA.

Burnham, K. P., and D. R. Anderson. 2002. Model selection and multimodel inference: a practical information-theoretic approach. Second edition. Springer-Verlag, New York, New York, USA.

Choquet, R., J.-D. Lebreton, O. Gimenez, A.-M. Reboulet, and R. Pradel. 2009. U-CARE: Utilities for performing goodness of fit tests and manipulating CApture-REcapture data. Ecography 32:1071-1074.

Choquet, R., A.-M. Reboulet, J. D. Lebreton, O. Gimenez, and R. Pradel. 2005. U-CARE 2.2. User manual. CEFE (Centre d'Ecologie Fonctionnelle et Evolutive), Montpellier, France.

Crawley, M. J. 2007. The R book. Statistical Papers 50:445446.

Duhem, C., P. Roche, E. Vidal, and T. Tatoni. 2008. Effects of anthropogenic food resources on Yellow-legged Gull colony size on Mediterranean islands. Population Ecology 50:91100 .

EU [European Union]. 2009. Emendation, 1999 directive. Council Directive on the Landfill of Waste. http://eur-lex.europa.eu/ LexUriServ/LexUriServ.do?uri=CELEX:31999L0031:EN:NOT

European Commission. 2008. Directive 2008/56/EC of the European Parliament and of the Council establishing a framework for community action in the field of marine environmental policy. European Parliament and the Council of the European Union, Strasbourg, France.

Fernández-Chacón, A., M. Genovart, R. Pradel, G. Tavecchia, A. Bertolero, J. Piccardo, M. G. Forero, I. Afán, J. Muntaner, and D. Oro. 2013. When to stay, when to disperse and where to go: survival and dispersal patterns in a spatially structured seabird population. Ecography 36:1117-1126.

Genovart, M., N. Negre, G. Tavecchia, A. Bistuer, L. Parpal, and D. Oro. 2010. The young, the weak and the sick: evidence of natural selection by predation. PLoS ONE 5:e9774.

Grémillet, D., L. Pichegru, G. Kuntz, A. G. Woakes, S. Wilkinson, R. J. M. Crawford, and P. G. Ryan. 2008. A junk-food hypothesis for gannets feeding on fishery waste. Proceedings of the Royal Society B: Biological Sciences 275:1149-1156.

Hadler, M. R., and A. P. Buckle. 1992. Forty five years of anticoagulant rodenticides - past, present and future trends. 
Proceedings of the Fifteenth Vertebrate Pest Conference 1992. Paper 36. http://digitalcommons.unl.edu/vpc15/36

Harding, A. M. A., J. Welcker, H. Steen, K. C. Hamer, A. S. Kitaysky, J. Fort, S. L. Talbot, L. A. Cornick, N. J. Karnovsky, G. W. Gabrielsen, and D. Grémillet. 2011 Adverse foraging conditions may impact body mass and survival of a high Arctic seabird. Oecologia 167:49-59.

Harris, M. P., S. N. Freeman, S. Wanless, B. J. T. Morgan, and C. V. Wernham. 1997. Factors influencing the survival of Puffins Fratercula arctica at a North Sea colony over a 20year period. Journal of Avian Biology 28:287.

Hatch, J. J. 1996. Threats to public health from gulls (Laridae). International Journal of Environmental Health Research 6:5-16.

Hobson, K. A. 2008. Using endogenous and exogenous markers in bird conservation. Bird Conservation International 18:S174-S199.

Lebreton, J.-D., T. Almeras, and R. Pradel. 1999. Competing events, mixtures of information and multistratum recapture models. Bird Study 46:S39-S46.

Lebreton, J.-D., K. P. Burnham, J. Clobert, and D. R. Anderson. 1992. Modeling survival and testing biological hypotheses using marked animals: a unified approach with case studies. Ecological Monographs 62:67-118.

Lott, C. A., T. D. Meehan, and J. A. Heath. 2003. Estimating the latitudinal origins of migratory birds using hydrogen and sulfur stable isotopes in feathers: influence of marine prey base. Oecologia 134:505-510.

Martínez-Abraín, A., G. Tavecchia, H. M. Regan, J. Jiménez, M. Surroca, and D. Oro. 2012. Effects of wind farms and food scarcity on a large scavenging bird species following an epidemic of bovine spongiform encephalopathy. Journal of Applied Ecology 49:109-117.

Mate, K. E., F. C. Molinia, and J. C. Rodger. 1998 Manipulation of the fertility of marsupials for conservation of endangered species and control of over-abundant populations. Animal Reproduction Science 53:65-76.

Mayol, J., M. Mayol, O. Domenech, J. Oliver, M. McMinn, and A. Rodriguez. 2012a. Aerial broadcast of rodenticide on the island of Sa Dragonera (Balearic Islands, Spain). A promising rodent eradication experience on a Mediterranean island. Aliens: The Invasive Species Bulletin (Newsletter of the IUCN/SSC Invasive Species Specialist Group) 32:29-32.

Mayol, J., J. Oliver, M. Mayol, M. McMinn, A. Rodriguez, and O. Domenech. 2012b. Sa Dragonera, campaña de desratización. Quercus 314:26-33. [In Spanish.]

McMinn, M.. 2010. Gavina Larus michahellis in Atles dels aucells nidificants de mallorca i Cabrera. Grup Balear d'Ornitologia i Defensa de la Naturalesa. Consell Insular de Mallorca, Palma de Mallorca. [In Spanish.]

Merrill, J. A., E. G. Cooch, Curtis, P. D. and McCorquodale. 2006. Managing an overabundant deer population by sterilization: effects of immigration, stochasticity and the capture process. Journal of Wildlife Management 70:268277.

Moreno, R., L. Jover, I. Munilla, A. Velando, and C. Sanpera. 2010. A three-isotope approach to disentangling the diet of a generalist consumer: the Yellow-legged Gull in northwest Spain. Marine Biology 157:545-553.

Morgan, B. 2000. Applied stochastic modelling. First edition. Arnold Publishers, London, UK.

Motis, A. 1989. El gavià argentat (Larus cachinnans) a Catalunya. Augment de l'espècie problemàtica propostes d'actuació. Direcció General del Medi Natural. Generalitat de Catalunya, Barcelona, Spain.

Natsumeda, T., H. Sakano, T. Tsuruta, K. Kameda, and K. Iguchi. 2015. Immigration of the common Cormorant Phalacrocorax carbo haneda into inland areas of the northern part of Nagano Prefecture, eastern Japan, inferred from stable isotopes of carbon, nitrogen and sulphur. Fish Science 81:131-137.
Navarro, J., D. Oro, A. Bertolero, M. Genovart, A. Delgado, and M. G. Forero. 2010. Age and sexual differences in the exploitation of two anthropogenic food resources for an opportunistic seabird. Marine Biology 157:2453-2459.

Newsome, T. M., J. A. Dellinger, C. R. Pavey, W. J. Ripple, C. R. Shores, A. J. Wirsing, and C. R. Dickman. 2015. The ecological effects of providing resource subsidies to predators. Global Ecology and Biogeography 24:1-11.

Oro, D. 1996. Effects of trawler discard availability on egg laying and breeding success in the Lesser Black-backed Gull Larus fuscus in the western Mediterranean. Marine Ecology Progress Series 132:43-46.

Oro, D. 1999. Trawler discards: a threat or a resource for opportunistic seabirds? Pages 717-730 in N. J. Adams and R. H. Slotow, editors. Proceedings of the 22nd International Ornithological Congress, Durban. BirdLife South Africa, Johannesburg, South Africa.

Oro, D. 2003. Managing seabird metapopulations in the Mediterranean: constraints and challenges. Scientia Marina 67:13-22.

Oro, D., M. Bosch, and X. Ruiz. 1995. Effects of a trawling moratorium on the breeding success of the Yellow-legged Gull Larus cachinnans. Ibis 137:547-549.

Oro, D., E. Cam, R. Pradel, and A. Martinez-Abrain. 2004. Influence of food availability on demography and local population dynamics in a long-lived seabird. Proceedings of the Royal Society B: Biological Sciences 271:387-396.

Oro, D., and R. W. Furness. 2002. Influences of food availability and predation on survival of Kittiwakes. Ecology 83:2516.

Oro, D., M. Genovart, G. Tavecchia, M. S. Fowler, and A. Martínez-Abraín. 2013. Ecological and evolutionary implications of food subsidies from humans. Ecology Letters $16: 1501-1514$.

Oro, D., and A. Martínez-Abraín. 2007. Deconstructing myths on large gulls and their impact on threatened sympatric waterbirds. Animal Conservation 10:117-126.

Oro, D., E. Mínguez, E. de Juana, and A. Martínez-Abraín. 2003. Mediterranean seabird conservation: what can we do? Scientia Marina 67(Supplement 2):3-6.

Oro, D., and R. Pradel. 2000. Determinants of local recruitment in a growing colony of Audouin's Gull. Journal of Animal Ecology 69:119-132.

Oro, D., R. Pradel, and J.-D. Lebreton. 1999. Food availability and nest predation influence life history traits in Audouin's Gull, Larus audouinii. Oecologia 118:438-445.

Parnell, A., R. Inger, S. Bearhop, and A. L. Jackson. 2008. SIAR: stable isotope analysis in R. R package, version 4.1.3. www.r-project.org

Pedro, P. I., J. A. Ramos, V. C. Neves, and V. H. Paiva. 2013. Past and present trophic position and decadal changes in diet of Yellow-legged Gull in the Azores Archipelago, NE Atlantic. European Journal of Wildlife Research 59:833-845.

Pedrocchi, V., D. Oro, and J. González-Solss. 1996. Differences between diet of adult and chick Audouin's Gulls Larus audouinii at the Chafarinas Islands, SW Mediterranean. Ornis Fennica 73:124-130.

Pierotti, R., and C. A. Annett. 1991. Diet choice in the Herring Gull: constraints imposed by reproductive and ecological factors. Ecology 72:319-328.

Pons, J.-M. 1992. Effects of changes in the availability of human refuse on breeding parameters in a Herring Gull Larus argentatus population in Brittany, France. ARDEA 80:143-150.

Pons, J.-M., and P. Migot. 1995. Life-history strategy of the Herring Gull: changes in survival and fecundity in a population subjected to various feeding conditions. Journal of Animal Ecology 64:592-599.

Pradel, R., C. Wintrebert, and O. Gimenez. 2003. A proposal for a goodness-of-fit test to the Arnason-Schwarz multisite capture-recapture model. Biometrics 59:43-55. 
Pugesek, B. H., and K. L. Diem. 1990. The relationship between reproduction and survival in known-aged california gulls. Ecology 71:811-817.

Ramos, R., F. Ramírez, J. L. Carrasco, and L. Jover. 2011. Insights into the spatiotemporal component of feeding ecology: an isotopic approach for conservation management sciences. Diversity and Distributions 17:338-349.

Ramos, R., F. Ramírez, C. Sanpera, L. Jover, and X. Ruiz. 2009. Diet of Yellow-legged Gull (Larus michahellis) chicks along the Spanish Western Mediterranean coast: the relevance of refuse dumps. Journal of Ornithology 150:265-272.

Sæther, B.-E., T. H. Ringsby, and E. Roskaft. 1996. Life history variation, population processes and priorities in species conservation: towards a reunion of research paradigms. Oikos 77:217-226.

Sanz-Aguilar, A., G. Tavecchia, R. Pradel, E. Mínguez, and D. Oro. 2008. The cost of reproduction and experiencedependent vital rates in small petrel. Ecology 89:3195-3203.

Seber, G. A. F. 2002. The estimation of animal abundance. Second edition. Blackburn, Caldwell, New Jersey, USA.

Servei de Protecció d'especies. 2011. Informe final del desarrollo de la campaña de desratización de Sa Dragonera. Conselleria de Medi ambient, Govern de les Illes Balears, Palma de Mallorca, Spain. [In Spanish.]

Steigerwald, E. C., J.-M. Igual, A. Payo-Payo, and G. Tavecchia. 2015. Effects of decreased anthropogenic food availability on an opportunistic gull: evidence for a sizemediated response in breeding females. Ibis 157:439-448.

Thomas, G. J. 1972. A review of gull damage and management methods at nature reserves. Biological Conservation 4:117127.

TIRME [Parque de Tecnologías Ambientales de Mallorca]. 2003. Informes d'activitats del projecte de control de gavines (L. michahellis) a Son Reus. Fundacio Natura Park, Palma de Mallorca, Spain.
Twigg, L. E., and C. Kent Williams. 1999. Fertility control of overabundant species: can it work for feral rabbits? Ecology Letters 2:281-285.

Verdú del Campo, M., J. Catalá Iborra, and F. J. García y Gans. 1995. Ecología alimenticia de Larus cachinnans y Larus audouinii en las islas columbretes: relaciones con el medio marino. Chioglossa 1:35-39. [In Spanish.]

Vidal, E., F. Medail, and T. Tatoni. 1998. Is the Yellow-legged Gull a superabundant bird species in the Mediterranean? Impact on fauna and flora, conservation measures and research priorities. Biodiversity and Conservation 7:10131026.

Vitousek, P. M., H. A. Mooney, J. Lubchenco, and J. M. Melillo. 1997. Human domination of Earth's ecosystems. Science 277:494-499.

Warburton, B., and B. G. Norton. 2009. Towards a knowledgebased ethic for lethal control of nuisance wildlife. Journal of Wildlife Management 73:158-164.

White, G. C., and K. P. Burnham. 1999. Program MARK: survival estimation from populations of marked animals. Bird Study 46:S120-S139.

Williams, B. K., J. D. Nichols, and J. M. Conroy. 2001. Analysis and management of animal populations. Academic Press, New York, New York, USA.

Witt, H.-H., J. Crespo, E. De Juana, and J. Varela. 1981. Comparative ecology of Aduouin's Gull Larus audouinii and the Herring Gull Larus argentatus in the Mediterranean. Ibis 123:519-526.

Zar, J. H. 2010. Biostatistical analysis. Fifth edition. Pearson, Upper Saddle River, New Jersey.

Zotier, R., V. Bretagnolle, and J.-C. Thibault. 1999. Biogeography of the marine birds of a confined sea, the Mediterranean. Journal of Biogeography 26:297-313.

Zuur, A. F., E. N. Ieno, N. Walker, A. A. Saveliev, and G. M. Smith. 2009. Mixed effects models and extensions in ecology with R. Springer, New York, New York, USA.

\section{Supplemental Material}

\section{Ecological Archives}

The Appendix is available online: http://dx.doi.org/10.1890/14-2090.1.sm

\section{Data Availability}

Data associated with this paper have been deposited in CEDAI (Centro de Datos Imedea):

M-ARRAY_Larus michahellis_Dragonera_2007_2013: http://cedai.imedea.uib-csic.es/geonetwork/srv/es/main.home?uuid= c867ca26-7b03-4dcb-ac26-7ef0ab536762

Stable Isotope Signature (CNS)_Larus michahellis_Dragonera 2004_2008_2011_2013: http://cedai.imedea.uib-csic.es/ geonetwork/srv/es/main.home?uuid=280c2ad4-5204-4dde-b703-2ece5625730f

Nest abundance_Larus michahellis_Dragonera_2008_2013: http://cedai.imedea.uib-csic.es/geonetwork/srv/es/main.home?uuid= be15329b-5f71-4b9c-bd02-5cddcb67a553 